\title{
Stable Production Technology for Horizontal Well Development in Shallow Water Delta Oilfield of Bohai Bay, China
}

\author{
Guangyi Sun, Qiongyuan Wu, Huijiang Chang, Xiaoming Chen, Shangqi Zhai \\ Bohai Petroleum Research Institute, China National Offshore Oil Corporation, Tianjin, China \\ Email: sungy@cnooc.com.cn
}

How to cite this paper: Sun, G.Y., Wu, Q.Y., Chang, H.J., Chen, X.M. and Zhai, S.Q. (2019) Stable Production Technology for Horizontal Well Development in Shallow Water Delta Oilfield of Bohai Bay, China. Open Journal of Yangtze Gas and Oil, 4, 258-269.

https://doi.org/10.4236/ojogas.2019.44021

Received: August 27, 2019

Accepted: October 7, 2019

Published: October 10, 2019

Copyright $\odot 2019$ by author(s) and Scientific Research Publishing Inc. This work is licensed under the Creative Commons Attribution International License (CC BY 4.0).

http://creativecommons.org/licenses/by/4.0/

\begin{abstract}
BZ Oilfield is a medium-sized oilfield with shallow delta facies deposits in Bohai Bay of China, compared with fluvial and delta facies oilfields, there is no mature experience for reference of reservoir configuration, well pattern arrangement and development model in offshore oilfields in China. In view of the difficulty in describing the reservoir configuration of shallow water delta, the single distributary sand dam in shallow water delta is characterized by well-seismic combination and multi-attribute constraints. The mathematical mechanism model of pinch-out position of sand body is established, fine characterization of BZ shallow water delta reservoir is put forward. The horizontal well pattern arrangement type for shallow water delta reservoir is proposed and the method of well pattern optimization based on vertical displacement theory is put forward. A method of inversion of reservoir connectivity using production dynamic data by numerical well testing is proposed and a new method for optimizing water injection rate in water injection wells is proposed aiming at the difficulty of recognizing injection-production connectivity of shallow water delta reservoirs. The fine configuration of BZ shallow water delta reservoir based on distributary sand dam is proposed, which guides the recognition of remaining oil distribution law. By deploying adjustment wells, the water flooding coincidence degree of actual drilling is $86 \%$ compared with that of pre-drilling prediction, which indicates that the research results of reservoir configuration can effectively guide the understanding of oilfield geology. Through the theoretical well arrangement type of vertical displacement of single sand body in horizontal wells of shallow water delta reservoir, a high water flooding recovery rate of $35 \%$ is achieved in primary well pattern. The connectivity coefficients of injection-production boundary of shallow water delta reservoir configuration are calculated, and the water injection distribution coefficients are obtained by normalizing the
\end{abstract}


directional coefficients. This paper presents a configuration method based on multi-attribute fusion under the constraints of sedimentary process. In this paper, a shallow water delta reservoir configuration method based on multi-attribute fusion constrained by sedimentary process is proposed, and the injection-production connectivity coefficient and injection well distribution coefficient of the configuration boundary are calculated.

\section{Keywords}

Production Stabilization Technology, Shallow Water Delta Oilfield, Reservoir Configuration, Horizontal Well, Optimized Water Injection

\section{Introduction}

BZ Oilfield is a medium-sized oilfield with shallow delta facies deposits in Bohai Bay of China. The development model of this type of oilfield has no mature experience for reference in offshore oilfields. Firstly, compared with the study of delta or fluvial facies reservoir configuration, shallow delta facies reservoir configuration is at the initial research stage in the industry, which brings difficulties for the understanding of reservoir connectivity and development adjustment [1] [2]. At the same time, the reservoir heterogeneity of shallow water delta facies oilfield is strong, what kind of well pattern should be adopted for development and how to carry out fine water injection are key problems in oilfield development. Based on this, this paper carries out shallow water delta reservoir research, development and exploitation mode research, and puts forward relevant innovative technological achievements, which are inseparable from BZ Oilfield to achieve stable production for ten consecutive years.

\section{Shallow Water Delta Reservoir Configuration Based on Distributary Sand Dam}

\subsection{Division of Distributary Sand Dam in Shallow Water Delta Reservoir}

The deposit type of BZ Oilfield is shallow-water delta based on distributary sand dam, which is the main constituent unit. Low-angle imbricate precursor under sub-parallel reflection background is developed inside the sand dam. This kind of shallow water delta mainly develops in the transgression area of relatively high water level [3], On the plane, there is a typical lobular distribution. The lobes are continuously deposited inside the lobes, and the inter lobes develop inter distributary bay deposits [4].

Oilfield seismic data have good continuity in phase axis, high signal-to-noise ratio and resolution (main frequency is about $45 \mathrm{~Hz}$ ), and good seismic data quality. Therefore, the distribution of single distributary sand dam can be quantitatively characterized by logging-seismic combination. With the help of edge detection method [5] [6] [7] [8], the paper constructs operators and uses edge 
detection method to highlight change points. In geological recognition, it is the boundary of weak connectivity or even disconnection of sand bodies, and it is also the overlapping position of diversion sand dams deposited at different stages, so as to guide us to accurately characterize a single diversion sand dam. Three sets of seismic forward models are designed for different contact relationships of single distributary sand dams which represent different geological meanings: Figure 1(a) represents the lateral superposition of heterogeneous single distributary sand dams. The thickness of distributary sand dams is approximately the same, but the physical properties are different; Figure 1(b) represents the lateral superposition of two diversion sand dams with different elevations. Figure 1(c) represents the laterally developed mudstone between two distributary sand dams. After defining the geological significance of the model, $45 \mathrm{~Hz}$ Reick wavelet is used to excite the reservoir. The reservoir thickness is $8 \mathrm{~m}$, the velocity of sandstone is $260 \mathrm{~m} / \mathrm{s}$, the density is $2100 \mathrm{~kg} / \mathrm{m}^{3}$, the velocity of mudstone is 3100 $\mathrm{m} / \mathrm{s}$, and the density is $2350 \mathrm{~kg} / \mathrm{m}^{3}$.
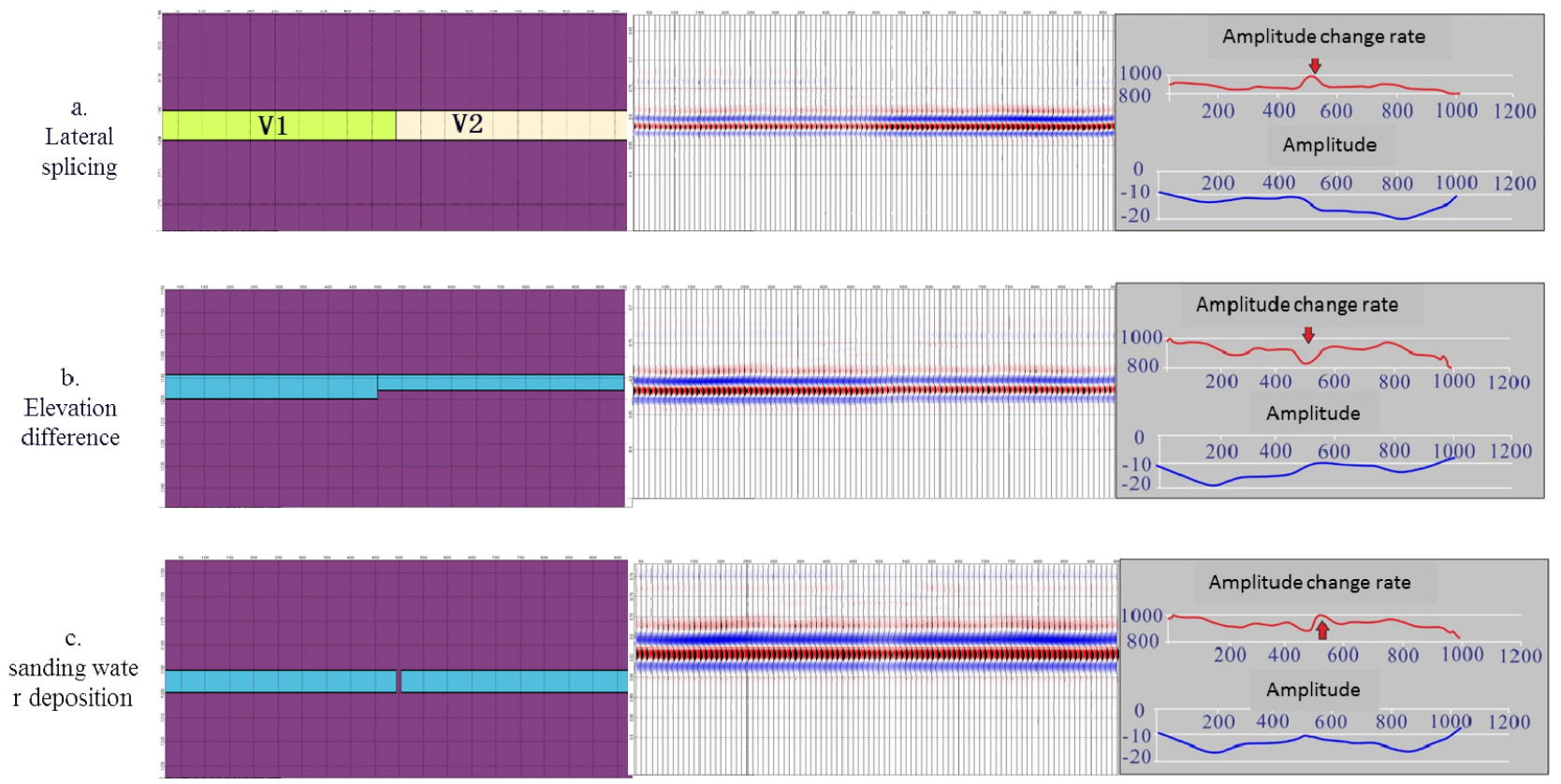

Figure 1. The seismic forwarding modeling.

The results show that the amplitude of heterogeneous single distributary sand dam changes slowly when it is overlapped laterally, but the amplitude change rate has a significant sudden change at the overlap of two-stage distributary sand dams, while there is no obvious change in the amplitude change rate of single distributary sand dam. The two diversion sand dams with different elevations overlap laterally, and the amplitude and amplitude change rate also show similar laws. Mudstone develops laterally between the two distributary dams, and the amplitude of mudstone shows a weak response in the mudstone development zone, while the amplitude change rate attribute produces two obvious mutation points, corresponding to the boundary of the mudstone zone. Generally speak- 
ing, compared with the traditional amplitude attributes, the amplitude change rate can better track the lateral contact point of a single distributary sand dam and indicate the lateral contact position of a single distributary sand dam (Figure 2).
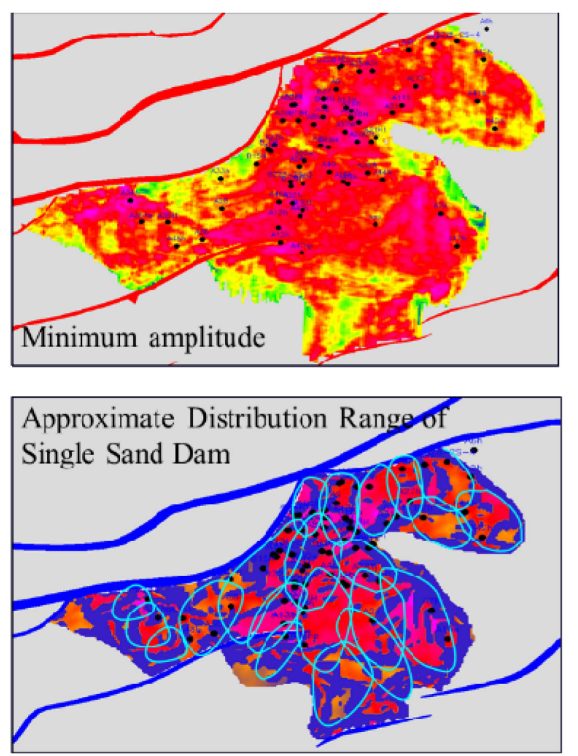
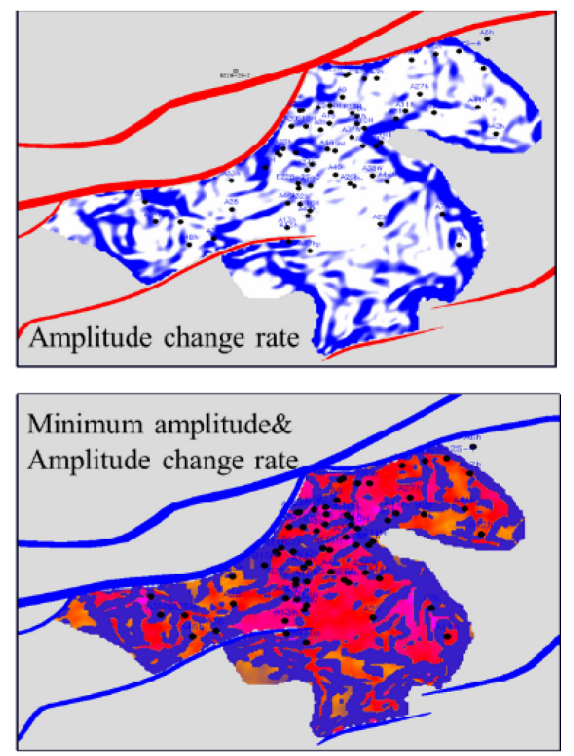

Figure 2. The distribution of multi-attribute fusion.

At the same time, considering that the amplitude attribute can better indicate the lateral change of reservoir, the amplitude and amplitude change rate are fused. After attribute fusion, the boundary of single sand body is clearer. Based on this, the approximate scope of single distributary sand dam can be determined preliminarily, and the transformation from seismic phenomenon to geological significance can be achieved.

\subsection{Boundary Characterization of Distributary Sand Dams}

Considering the multi-stage deposits along the source of distributary sand dams, different identification methods are adopted for the lateral and along-source boundaries. Lateral facies mainly consist of logging facies and seismic facies in dense well pattern area. Identification marks include elevation difference, lateral superposition and hydrostatic deposition. The corresponding seismic events show local dislocation, amplitude and frequency variation. At the same time, lateral boundary is delicately characterized by combining dynamic data such as horizontal wells and tracers. In BZ Oilfield, low-angle foreset is developed under the background of sub-parallel reflection at the top of the main oil formation. Therefore, in view of the parallel source boundary, from the point of view of sedimentary process, the single-stage distributary sand dam along the source is quantitatively characterized by foreset correlation in the isochronal stratigraphic framework of single sand body.

In order to improve the identification accuracy, in this paper drilling data are 
used to quantitatively calculate the pre-accumulated dip angle of single-stage distributary sand dam, abstract the theoretical model based on the pre-accumulated dip angle (Figure 3 ), and quantitatively calculate the boundary by using the theoretical model, which greatly improves the accuracy of boundary characterization.
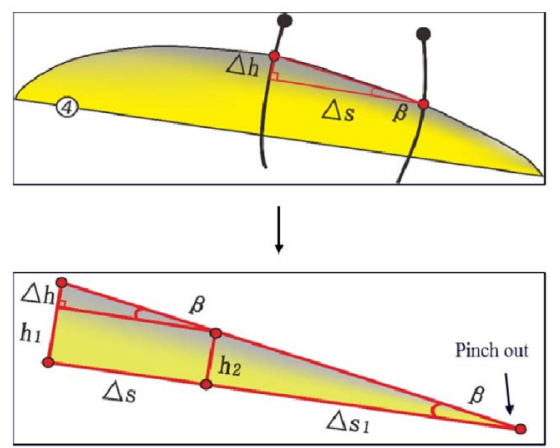

Figure 3. The theoretical calculation model for boundary of distributary sand dam.

$$
\begin{gathered}
\beta=\arctan (\Delta h / \Delta s) \\
\Delta s_{1}=h_{2} / \tan \beta=h_{2} \times \Delta s / \Delta h
\end{gathered}
$$

Among them, $\beta$ is the forward dip angle, $\Delta s_{1}$ is the externally extinguishing distance of the pre-accumulated sand, $\Delta h$ is the vertical distance of the pre-accumulated sand body of two wells in the same period, $\Delta s_{1}$ is the distance between the two wells, and $h_{2}$ is the vertical depth of the sand body drilled in the well.

By taking the main sand body 1 - 1167 as an example, 23 single-origin distributary dams are identified at three stages by lateral and parallel source bi-directional constraints. Each single sand dam has a thickness of $2.5-7 \mathrm{~m}$, a length of $600-1300 \mathrm{~m}$, a width of $300-600 \mathrm{~m}$, and a width-thickness ratio of 90 - 140 which has a good linear relationship. Among them, the dip angle of the first stage is about 0.35 degree, the second stage is 0.23 degree, and the third stage is 0.18 degree. Generally speaking, the evolution of the first stage is "early fore-accumulated, and the later stage is gradually over-accumulated" (Figure 4).

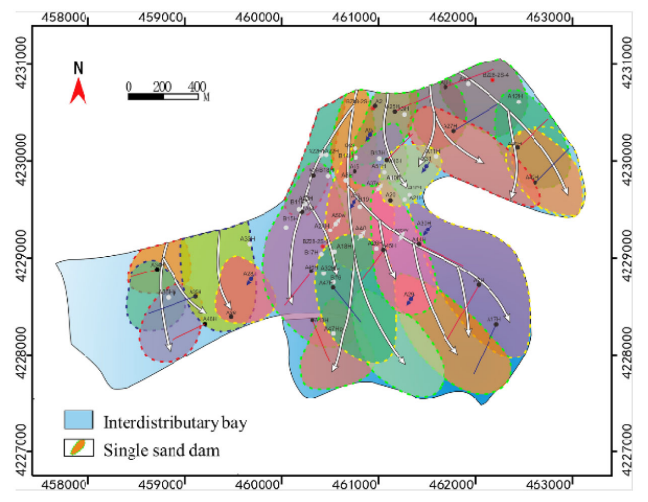

Figure 4. The results of 1 - 1167 sand body reservoir configuration. 
BZ Oilfield has a relatively gentle slope and relatively stable structure. Sand body distribution is mainly controlled by the formation process (source supply, lakeshore migration). The contact pattern of distributary sand dam is well coupled with its formation process. At the initial stage of sedimentation, the water body has strong energy and more sand, and the sand body accumulates at the large scale in the direction of lake basin and overlaps vertically. With the increase of the advancing distance to the lake basin, the inertia force energy weakens rapidly, the friction force gradually dominates, the sand body's fore-accumulation ability weakens, and the vertical main body overlaps. In the late sedimentary period, the supply of sand is weak. After long-distance shoreline migration, the sand bodies do not have the ability to accumulate. At this time, the vertical sand bodies are mainly superimposed by the main body. In the plane, the distributary sand dam also shows three splicing patterns, the early sand body is "free discrete with" lateral migration, and the distributary dam is mostly separated by mudstone laterally. As the low-lying areas in the estuary area are occupied by distributary sand dams at the early stage, the later distributary sand dams gradually look for space unloading deposits on both sides of the low-lying areas, and the distributary sand dams are mostly joined by side-to-side splicing. At the late stage of sedimentation, the supply of sand is weak, and the lateral migration ability is basically not available. The main contact pattern between distributary dams is lateral splicing.

The recognition of reservoir configuration is applied in geological model, which deepens the recognizing of remaining oil distribution. From 2016 to 2018, 14 wells were implemented to tap the potential of remaining oil. Compared with the prediction, the conformity of actual drilling water flooding is $86 \%$, which shows that the research results of reservoir configuration can effectively guide the oilfield geological cognition.

\section{Horizontal Well Development Technology in Shallow Water Delta Oilfield}

\subsection{Well Pattern Arrangement Technology for Horizontal Wells with Single Sand Body}

The overlapping relationship of distributary sand dam in shallow water delta reservoir of BZ Oilfield is complex, which will affect injection-production connectivity. This factor should be fully considered in well pattern deployment. Directional well pattern has limited sweep range, and it is difficult to achieve dense well pattern distribution due to the limitation of offshore platforms. Therefore, sparse directional well pattern will cause certain injection-production connectivity problems. Horizontal wells have the characteristics of large drainage area and wide sweep range. Deployment of horizontal well pattern based on the shape of distributary sand dam can minimize the injection-production connectivity problem caused by the overlapping of distributary sand dam. At the same time, the reservoir scale of single sand body in BZ Oilfield is quite different, and the overlapping area of sand body is small, Therefore, a horizontal well 
pattern based on single sand body has been formed. The main types of well pattern are horizontal well parallel well pattern and horizontal well staggered well pattern, Directional wells are used to develop high sand overlay areas, The application ratio of horizontal wells is more than $70 \%$. The technical limits of horizontal well pattern are as follows: the average thickness of well distribution area is $7.8 \mathrm{~m}$, well-controlled reserves are about $60 \times 10^{4} \mathrm{~m}^{3}$, the injection-production well ratio is $1: 2$, the injection-production well spacing is 300 $500 \mathrm{~m}$, and the horizontal section length is $300-450 \mathrm{~m}$. The corresponding injection-production ratio is more than $80 \%$, and the control degree of water drive reserves is more than $80 \%$. The lower limit of oil column height for horizontal production wells deployed near the transition zone is $5.0 \mathrm{~m}$ (Figure 5).

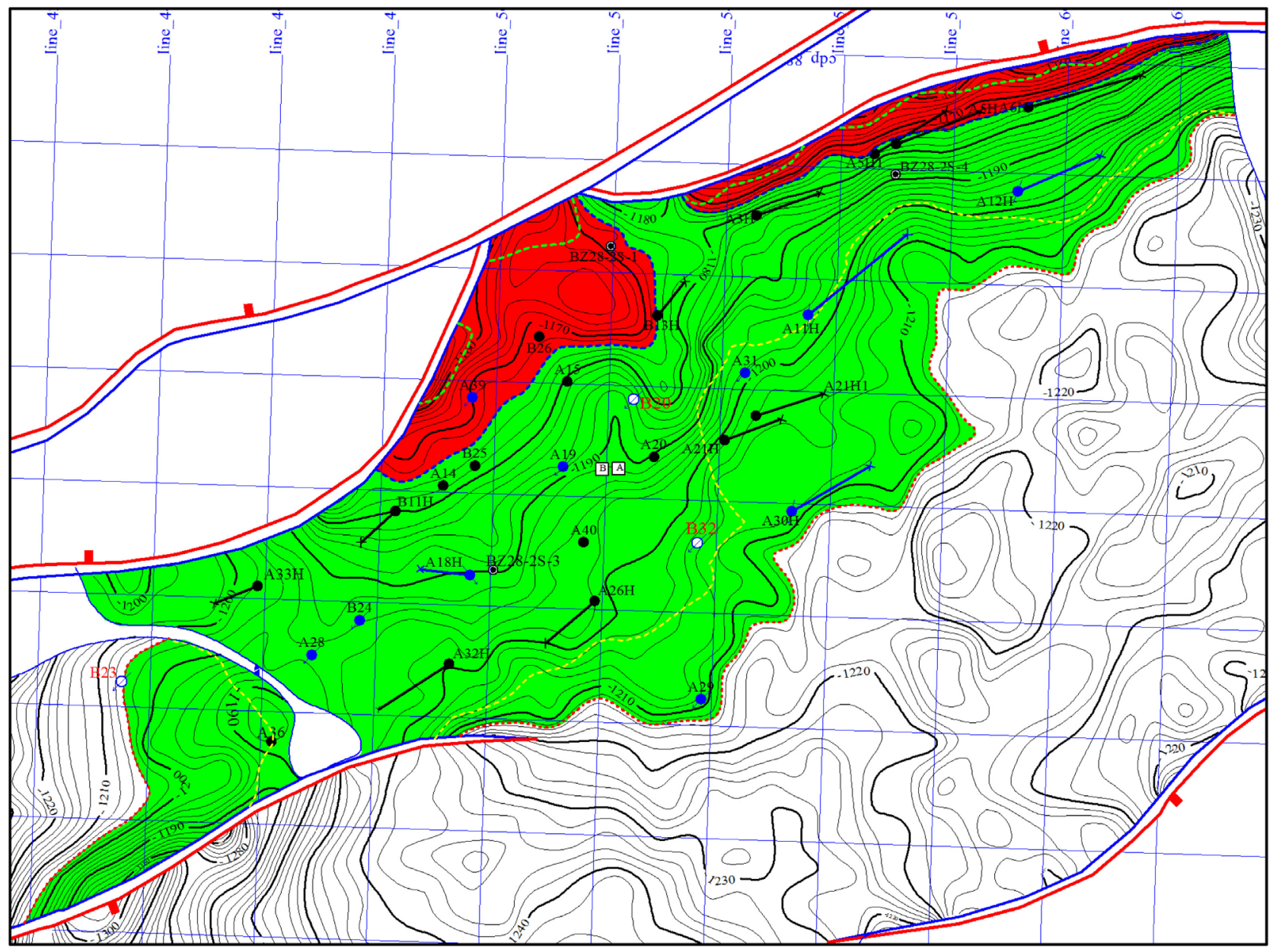

Figure 5. The well pattern arrangement in BZ Oilfield (1-1195-1 sand body).

In the process of well pattern optimization, the characteristics of channel distribution [9] [10] [11] and the theoretical well pattern technology of vertical oil displacement [12] [13] [14] are fully considered. That is to say, the injection-production well pattern is formed in the vertical or reverse direction of the channel. This is because when the injection water advances along the sedimentary direction, it is easy to move along the larger channel formed during the 
original sedimentation, with less resistance, faster advance and poor displacement effect. When advancing upstream or laterally, it is in the direction of reverse deposition or vertical deposition, with larger resistance and slower progress. Injection water is forced into smaller channels, and the oil displacement effect is better. By taking Well $\mathrm{B} 11 \mathrm{H}$ as an example, the production well is infilled between sand bodies, which corresponds to Well $\mathrm{A} 18 \mathrm{H}$ of water injection well and is influenced by injection Well $\mathrm{A} 18 \mathrm{H}$. The direction of water drive is perpendicular to the direction of channel development (Figure 6). Well B11H was put into operation at the end of 2014, when the comprehensive water cut of the oilfield was $69 \%$. The anhydrous recovery period of Well $\mathrm{B} 11 \mathrm{H}$ is 147 days after putting into operation, and the development effect is very good (Figure 7). The vertical displacement well arrangement method can maximize the recovery factor of production wells during waterless production period. According to the statistics, the average anhydrous recovery period of primary well pattern in BZ Oilfield is 378 days, and the average recovery rate in anhydrous production period is $22.3 \%$, which is higher than other well patterns.

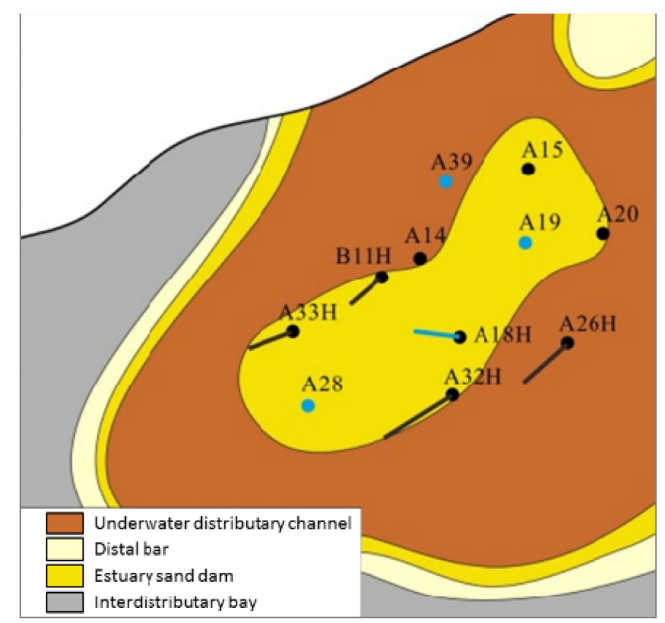

Figure 6. The well pattern arrangement of 1 - 1195 sand Sand body.

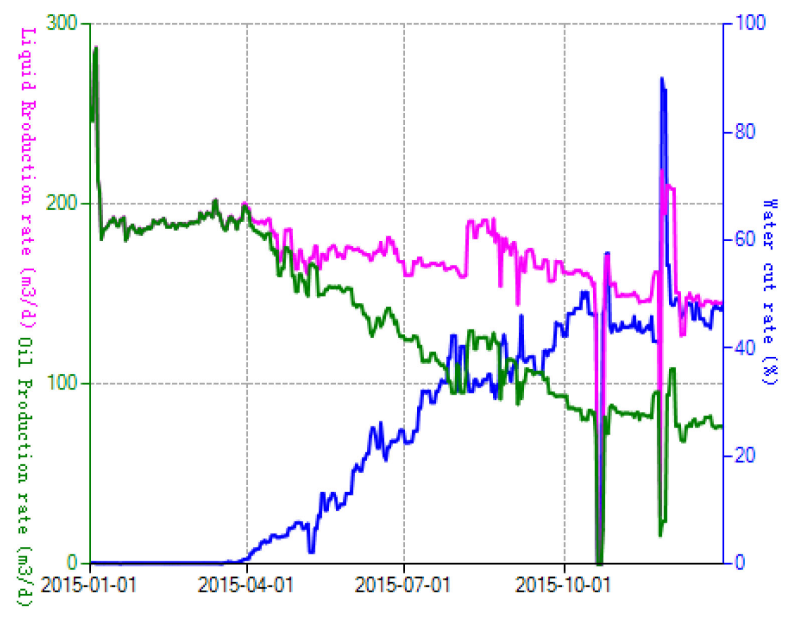

Figure 7. The production curve of Well $\mathrm{B} 11 \mathrm{H}$. 


\subsection{Water Injection Optimization of Shallow Water Delta Reservoirs}

Shallow water delta reservoir configurational boundaries have a certain shielding effect on injection and production, the impact degree is usually different, which is hard to understand clearly. For oilfield water injection, it directly affects the split recognition of water injection volume in injection wells. Therefore, it is difficult to implement fine water injection in shallow water delta reservoir. In oilfield production process, it is found that the pressure response of production wells is different when injection-production relationship is formed in different configuration units. Based on this, a new method of using production well pressure data is proposed to reflect the interface connectivity of configurations.

The numerical well testing technology is used with PEBI gird, which can combine local fine grids with basic coarsening grids and can make use of fine grids near wellbore and faults, and sparse basic grids far from wellbore. In this way, the geological characteristics of oil and gas reservoirs can be truly depicted, and the speed and accuracy of well test operation can be improved [15] [16] [17]. Firstly, according to the research results of shallow water delta reservoir configuration characterized in Saphir Software, the Saphir numerical well test model is established. Then, the configuration units of production wells are determined, and the configuration boundaries affecting the connectivity of injection and production are found. Finally, the injection-production connectivity coefficients between different configurations are fitted until the pressure fitting accuracy of production wells is the highest.

Take production Well $\mathrm{A} 45 \mathrm{H}$ as an example, it is considered that the injection-production connectivity coefficient of the well is 1 in the injection Wells A29 and A47H before configuration, which means completely connection. But the pressure fitting accuracy of Well $\mathrm{A} 45 \mathrm{H}$ is poor at that time. After more than 100 hours, the pressure derivative curve is warped up, which indicates that the well is affected by the boundary. Then a numerical well test model is established, two configurational boundaries have been established on both sides of Well $\mathrm{A} 45 \mathrm{H}$. Then, the injection-production connectivity coefficient of configuration boundary is fitted. The pressure derivative curve of Well $\mathrm{A} 45 \mathrm{H}$ is well fitted when the injection-production connectivity coefficient of the left and right configuration boundaries is 0.3 and 0.8 , respectively, which means the connectivity between Well $\mathrm{A} 45 \mathrm{H}$ and Well $\mathrm{A} 47 \mathrm{H}$ is poorer than A29. It provides an effective method to recognize the injection-production connectivity at the configuration interface (Figure 8).

By using this method, the injection-production connectivity coefficients of different configurations of interfaces can be inverted, The range of this value varies from 0 to 1 , which indicates that the connectivity of injection and production is improved from bad to good. By normalizing all injection-production connectivity coefficients in different directions, the injection distribution coefficients of injection wells and effective production wells can be obtained. As shown in Table 1, there is one injection well and four production wells in a 
group, the production wells are $\mathrm{PRO} 1-\mathrm{PRO} 4$, respectively. The water injection distribution coefficients of four production wells are generally given in conjunction with production performance before using this method with certain subjective factors. The water injection distribution coefficient obtained by normalization of connectivity coefficient takes full account of reservoir heterogeneity, so it is more accurate. In addition, the splitting coefficient is also applicable to irregularly combined well pattern, which can effectively guide the optimization of oilfield water injection.

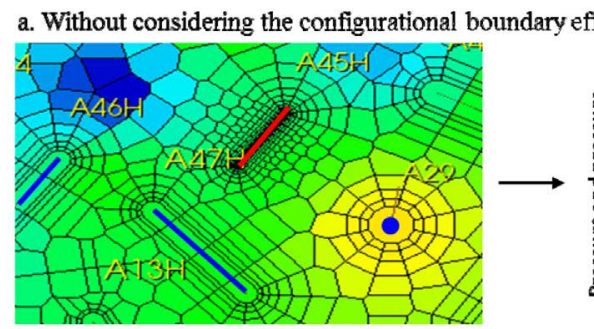

b. Consideration of configuration boundary effect
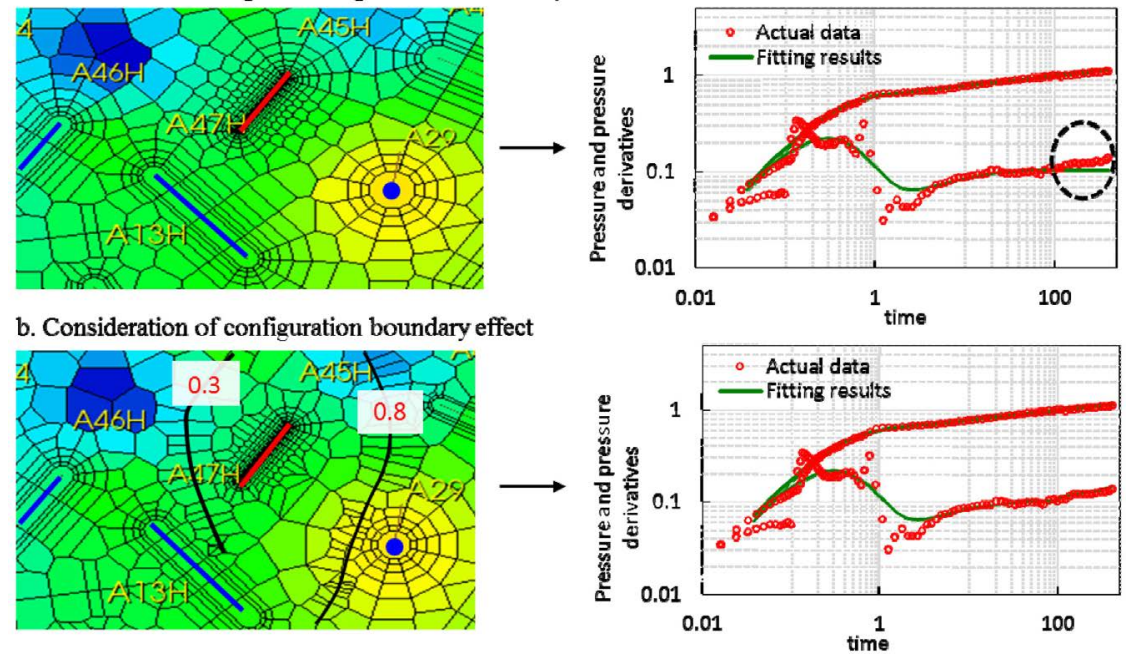

Figure 8. The calculation of injection-production connectivity coefficient based on pressure data of well $\mathrm{A} 45 \mathrm{H}$.

Table 1. The water injection coefficient optimization of water injection wells.

\begin{tabular}{cccc}
\hline $\begin{array}{c}\text { Well } \\
\text { number }\end{array}$ & $\begin{array}{c}\text { Old splitting } \\
\text { coefficient }\end{array}$ & $\begin{array}{c}\text { Computed } \\
\text { Connectivity } \\
\text { State Coefficient }\end{array}$ & $\begin{array}{c}\text { New splitting coefficient after } \\
\text { normalization of connectivity } \\
\text { condition coefficient }\end{array}$ \\
\hline PRO1 & 0.10 & 0.15 & 0.07 \\
PRO2 & 0.20 & 0.30 & 0.14 \\
PRO3 & 0.30 & 0.70 & 0.33 \\
PRO4 & 0.40 & 1.00 & 0.47 \\
\hline
\end{tabular}

\section{Conclusions}

1) Reservoir configuration research methods in shallow water delta are proposed, including boundary characterization of distributary bar and distributary bar. Reservoir configuration knowledge is expressed in geological model. The coincidence rate between actual drilling water flooding degree and predicted value is higher for $86 \%$.

2) The development model of horizontal well pattern in shallow water delta is put forward. According to the theory of vertical displacement, the average waterless recovery period of primary well pattern in BZ Oilfield is 378 days, and the 
average recovery rate of waterless recovery period is $22.3 \%$, which is higher than other well patterns.

3) The interfacial connectivity of shallow water delta reservoir configurations is studied by logging-seismic combination and numerical well testing, and a new method for determining the distribution coefficient of injection wells is proposed.

\section{Conflicts of Interest}

The authors declare no conflicts of interest regarding the publication of this paper.

\section{References}

[1] Xu, Y.X., Chai, X.C., Liao, X.W., et al. (2015) High-Efficiency Development Technology and Practice of Offshore Complex Fluvial Oilfields. Petroleum Geology and Engineering, 29, 69-72.

[2] Gu, W.M. and Hou, Y.W. (2014) Safety Optimization of Water Injection Technology for Offshore Complex Fluvial Oilfields. Journal of Petroleum and Natural Gas, 36, 150-153.

[3] Zhu, Y.J., Yin, T.J. and Liu, L.L. (2011) Research Progress and Discussion on Shallow-Water Delta Deposits. Journal of Petroleum and Natural Gas, 33, 22-26.

[4] Zhang, X.T., Zhou, X.H., Li, J.P., et al. (2014) Study on "Shallow Delta front Sandbody System" in Open Sedimentary Environment. Journal of Sedimentation, 32, 260-269.

[5] Wei, W.B. and Rui, X.T. (2006) Research on Image Edge Detection Method. Computer Engineering and Application, 42, 88-91.

[6] Duan, R.L., Li, Q.L. and Li, Y.H. (2005) Review of Image Edge Detection Methods. Optical Technology, 31, 415-419.

[7] Zhao, J.T., Yu, C.X., Peng, S.P., et al. (2016) Discontinuous and Heterogeneous Geophysical Detection Method Based on Sparse Inversion of Seismic Imaging Data. Journal of Geophysics, 59, 3408-3416.

[8] Xu, H.Q., Gui, Z.X. and Sun, Z.D., (2011) Application of Edge Detection Technology in Seismic Attributes. Oil Geophysical Exploration, 46, 126-128.

[9] Hu, G.Y., Chen, F., Sun, L.C., Fan, T.G., et al. (2013) Application of High Resolution Sequence Stratigraphy in Development of Fluvial Oilfields. Journal of Sedimentation, 31, 600-607.

[10] Qin, R.S., Liao, X.W., Feng, X., et al. (2014) Superimposition Types and Dynamic Response Characteristics of 3 Small Channel Sandbodies of Oil Group I in Southern Section of Qinhuangdao 32-6 Oilfield. Petroleum Geology and Recovery, 21, 5-19.

[11] Liu, J.M. and Xu, S.Y. (2003) Sedimentary Model of Fluvial Facies Reservoir and Control of Remaining Oil Distribution. Journal of Petroleum, 24, 58-62.

[12] Li, D.P. (2009) Theory of Vertical Oil Displacement. Daqing Petroleum Geology and Development, 28, 66-73.

[13] Chen, C.H. (2016) Study on the Effect of Vertical Heterogeneity of Reservoir on Oil Displacement Efficiency. China University of Geosciences, Beijing.

[14] Fu, G.M., Liu, Y.H. and Ning, Z.Q. (2006) Optimum Design of Well Pattern for Water Injection Development in Fractured Ultra-Low Permeability Reservoirs. 
Journal of Petroleum and Natural Gas, 28, 94-96.

[15] Lv, Z.B., Huo, C.L. and Xu,J. (2019) Research on Modeling Technology of Discrete Fractures Based on Unstructured Mesh. Journal of Chongqing University of Science and Technology: Natural Science Edition, 21, 25-29.

[16] Yang, Y.L., Jing, J. and Yang, Z.J. (2014) Realization Technology of Complex Geological Body Mesh Generation in Multiphase Flow Numerical Simulation. Journal of Jilin University (Engineering Edition), 45, 1281-1285.

[17] Cha, W.S., Li, D.L. and Zhang, L.J. (2013) Research on PEBI Mesh Generation Method. Well Testing, 22, 23-29. 